\title{
EFFECTS OF CURRICULUM DESIGN ON STUDENTS' CREATIVE POTENTIAL DEVELOPING - A CASE STUDY ON STUDENTS IN THE DEPARTMENT OF BUSINESS MANAGEMENT
}

\author{
Pao-Cheng LIN $^{1}-$ Pei-Kuan LIN $^{2}$ \\ ${ }^{1}$ Dept. of Business Administration, Taoyuan Innovation Institute of Technology, Taoyuan, Taiwan \\ R.O.C.E-mail:pclin@tiit.edu.tw \\ ${ }^{2}$ Dept. of Business Administration, Asia University, Taichung, Taiwan R.O.C. \\ E-mail:linpk@asia.edu.tw (corresponding author)
}

The rapid advance of science technology and civilization has resulted in people's activities being more complicated as various new problems are likely to occur at any time. Problem-solving abilities therefore become a basic competence to survive in modern societies. In the problem-solving process, the development of creativity is required to break through dilemmas. School education aims to cultivate students' decision-making and problem-solving competence. Nonetheless, the educational approaches and contents in Taiwan stress too much on mastery learning, and ignore the development of curiosity and creative potential.

Aiming at the students in the department of business management in national universities in Taiwan, total 300 copies of questionnaires are distributed, and 187 valid copies are retrieved, with the retrieval rate $62 \%$, in which each retrieved copy is regarded as a valid sample. The research findings show that Curriculum Design presents partially positive effects on Fluency, Flexibility, Originality, and Elaboration in Creative Potential Developing and Background Variables reveal significant moderating effects on the correlations between Curriculum Design and Creative Potential Developing.

Keywords: Curriculum Design, Creative Potential Developing, creativity, flexibility, originality

\section{INTRODUCTION}

The citizens' creativity is a critical key in the enhancement of a nation's competitiveness; the Lack of creativity will lead to sluggish social development, the country will be eliminated. Promoting students' originality therefore becomes the key educational objective. Sternberg and Lubart (1999) mentioned that what changed the history and brought spiritual cultural heritage for human beings was creation, not 
discovery. Apparently, Creativity, as the key human resource in the $21^{\text {st }}$ century, is worth being cultivated. A student's originality mainly comes from learning activities; both class teaching and group activities present the function of encouragement as various activities could inspire the potential developing, train the reconciliation development of sensory abilities, cultivate the adaptation to strange environments, and further present curiosity and desire for knowledge about the surrounding affairs. A teacher could also encourage the students solving problems with discovery and thinking through real activities, which is considered as the creative competence. The original thoughts could construct newer and more original ideas by integrating some creative thinking to become more useful conception with better reference value (Amabile 1983).

In face of future challenges, a lot of entrepreneurs in Taiwan indicate that international capability, EQ and problem-solving abilities, and the ability to apply technology are the essential competence of talents, in which problem-solving abilities are the ultimate objective of creative thinking. Nevertheless, the students, under present educational systems, could not do anything when facing problems and are lack of originality. Such a problem should be faced and introspected by every educator. Apparently, promoting students' Creative Potential Developing is worth emphases and discussions in education. What is more, it will be a competition between technology and brain in the $21^{\text {st }}$ century; Taiwanese people could continuously play a key role in the world by breaking through the convention and actively promoting various curricula based on Creative Potential Developing.

\section{DEFINITION AND RESEARCH HYPOTHESIS IN LITERATURE}

\subsection{Curriculum Design}

The key idea of current Curriculum Design is the presentation of multiple expositions, emphasizing that curricula should be generated through the interaction between learners and instructors. In the later period of $20^{\text {th }}$ century, a lot of issues and theories appear in academia, such as multicultural perspective, Postmodernism, and Constructivism, impacting the contents of Curriculum Design (Feldhusen 1980). Before 1970, curricula were deeply affected by Modernism, when the fundamental theory of curricula was Tyler model, which was an objective-oriented model. Considering curricula as a tool, the students would be shaped as the desired citizens when the basic knowledge was set for the students to master (György 2014). Curricula were like an administration technique without considering the factors of student traits and diverse educational phenomena (Wright and Fesler 1990). Curriculum Platform, Education Deliberation Process, and Design were 
the elements of naturalistic model in Curriculum Design, aiming to loyally present the real situation of curriculum development (Davis 1986; Walker 1990). Banks (1996) clarified the Curriculum Design process and value orientation in Constructivism with the actual educational descriptions of such three elements. (1) Curriculum Platform. It referred to the prior ideas of a curriculum developer, including the belief, value, hypothesis, purpose, and especially the curriculum meaning and educational perspective. (2) Deliberation Process. Based on Curriculum Platform, the necessary relationship and real relationship between educational objectives and education strategies were considered and definitely indicated the teaching and learning approaches and contents; particularly, learning approaches, teaching approaches, and educational objectives were regarded as interactive, rather than being determined by educational objectives. (3) Design Development. Curriculum Design emphasized the curriculum design and development in classes, stressed on the dynamic process of teacher-student interaction in classrooms, and insisted on the curriculum design and development in classroom situations. Teachers should verify the curricula and practice the principles of the curricula in the teaching process and introspected the teaching to promote the teaching quality.

\subsection{Creative Potential Developing}

Originality or Creativity has been a primary concept in the past years that education reformers advocate originality instruction and inspire learners' creativity. Psychologists pointed out Divergent Thinking as the source of encouraging potential and enhancing creativity, and innovation was a key competence in the knowledge economy era (Lin et al. 2014). Research on originality has been largely emphasized since Guild Ford called on emphasizing students' originality education in American Psychological Association in 1950. Originality was regarded in Behaviorism as an interaction. For example, a person was likely to make efforts to acquire more praise when he/she was rewarded. Originality, on the other hand, was considered in Cognitive Psychology, as a cognitive ability, the interaction among intelligence, personality, motive, and environment. For instance, a teacher would design teaching plans according to the students' characters and personality traits, precede instruction, record the students' reaction, and improve the instruction to create distinct teaching approaches (Parnes 1967). Generally speaking, the originality behaviors were broadly defined in Cognitive Psychology, about everywhere in our lives.

Researchers considered originality as the ability, such as the ability to innovate a brand new object, to connect present elements to become a new relationship, to solve problems, or to create life (Biagetti and Scicchitano 2013). In other words, 
originality could be a new thought, a new idea, a new object, a new product, a new process, a new art work, a new performance, or a newly interpreted expression (Morrison and Johnston 2006). In Guilford's (1956) "Structure of Intelligence", originality was considered as a divergent thinking ability, a high-level cognition process different from intelligence.

Johnson (1993) and Guilford indicated divergent thinking as the originality ability of human beings. Such creative potential contained the following factors.

(1) Fluency. Flexible and fluent mind allowed expressing several concepts in a short period of time, using more text words, and forming more associations. (2) Flexibility. The thinking was changeable but not bounded by convention. (3) Originality. The thinking performance was extraordinary, new methods could be proposed to deal with affairs, and unique opinions could be proposed for complicated problems. (4) Elaboration. One was accustomed to deliberate thinking, precisely analyzing affairs to pursue the perfection. Elliott (1991) pointed out the thinking process of originality as the "problem-solving" process of a creator. Sternberg and Lubart $(1995,1999)$ indicated that originality should cover intelligence, knowledge, cognitive style, personality, motive, and environment. Harris (2008) also mentioned originality as the combination of cognitive and interactive factors that a perfect Creative Potential Developing should consider personal factors (including personal character, motive, and personality) and environmental factors (containing family, school, organization, and social culture) and emphasize the real outputs (Davis 1997). Nevertheless, most research on originality and creativity focused on paper-based psychological measurement, in which the indicators were based on the dimensions for divergent thinking constructed by Guildford (1968), including Fluency, Flexibility, Originality, and Elaboration (Kincheloe 1993). Consequently, the four indicators are applied to the observation and evaluation of Creative Potential Developing in this study.

\subsection{Research hypothesis}

To cope with the advance of time and the change of society, domestic educational policies are changing with international education trend. However, it generally supports that originality could be trained and cultivated, the idea of training and cultivating the citizens' originality through Curriculum Design has been taken into account. Ausubel et al. (1978) considered to cover individual development, social culture, and natural environment in the curricula of national education, and the learning areas of Language Arts, Health and Physical Education, Social Studies, Art and Humanities, Mathematics, Science and Technology, and Integrative Activities should be provided (Hocevar 1981). Visual Art, Music, and Per- 
formance Art were covered in Art and Humanities, aiming to cultivate students' art competence, encourage the active participation in art activities, enhance the art appreciation capability, cultivate the delight of life, and inspire the creative potential and healthy development of personality (Stringer 1996). Summing up the theories of Organon and Essentialism, it was concluded that Curriculum Design aimed to inspire spontaneity, creativity, and personality development, while Essentialism aimed to inspire knowledge abilities and creation abilities (Lytton 1972). From present Curriculum Design policies in Taiwan, creation and knowledge understanding are emphasized to express personal creativity, feeling, and opinions; and creation and knowledge competence tends to cultivate students' Creative Potential Developing. Creative thinking is generally utilized for inspiring students' creative potential to cultivate the creativity and problem-solving ability (Noffke 1997).

Accordingly, the following hypotheses are proposed in this study.

H1: Curriculum Design presents significantly positive effects on Fluency in Creative Potential Developing.

H2: Curriculum Design shows remarkably positive effects on Flexibility in Creative Potential Developing.

H3: Curriculum Design reveals notably positive effects on Originality in Creative Potential Developing.

H4: Curriculum Design has significantly positive effects on Elaboration in Creative Potential Developing.

H5: Gender presents remarkable moderating effects on the correlations between Curriculum Design and Creative Potential Developing.

H6: Family Condition shows notable moderating effects on the correlations between Curriculum Design and Creative Potential Developing.

H7: School Year reveals significant moderating effects on the correlations between Curriculum Design and Creative Potential Developing.

\section{RESEARCH STRUCTURE AND SAMPLING SUBJECT}

\subsection{Conceptual framework}

Concluding the above literatures, the conceptual framework (Figure 1) is drawn to discuss the correlations between demographic variables, Curriculum Design and Creative Potential Developing. 
\begin{tabular}{ll} 
Curriculum Design & $\begin{array}{l}\text { Creative Potential } \\
\text { Developing }\end{array}$ \\
\hline
\end{tabular}

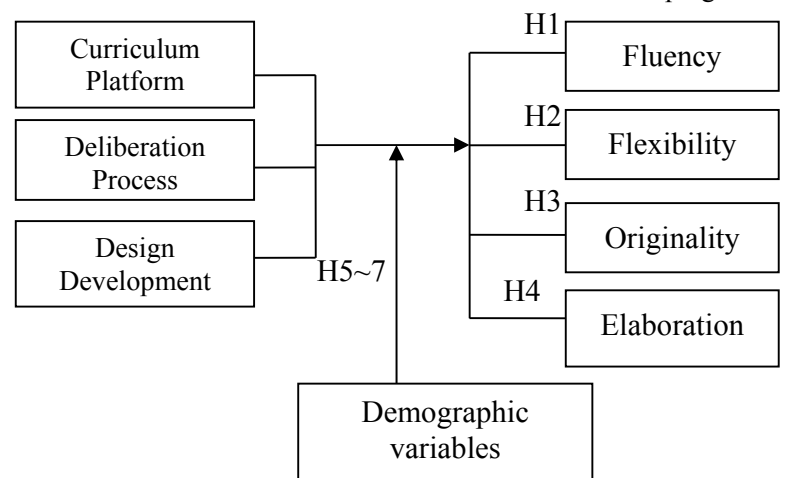

Figure 1. Conceptual framework of this study

\subsection{Research samples and sampling data analysis}

The students in the department of business management in national universities in Taiwan are distributed 300 copies of questionnaires. Total 187 valid copies are retrieved, with the retrieval rate $62 \%$, in which each retrieved copy is regarded as a valid sample. The statistical software, SPSS, is utilized for analyzing the data of the questionnaires, and Factor Analysis, Reliability Analysis, Regression Analysis, and Analysis of Variance are applied to testing the research hypotheses.

\subsection{Analysis}

With Regression Analysis to understand the correlations between Curriculum Design and Creative Potential Developing, Analysis of Variance is further utilized for exploring the effects of demographic variables on the correlations between Curriculum Design and Creative Potential Developing.

\section{ANALYSIS OF RESULT}

\subsection{Factor Analysis}

The dimensions and questionnaire for Curriculum Design were referred to Tsai (2008), from which three factors were extracted with Factor Analysis, including Curriculum Platform (eigenvalue $=3.428, \alpha=0.81$ ), Deliberation Process (ei- 
genvalue $=2.743, \alpha=0.85$ ), and Design Development (eigenvalue $=1.996, \alpha=$ $0.84)$. The covariance explained achieved $80.468 \%$.

The dimensions and questionnaire for Creative Potential Developing were referred to Guildford (1968) and Wu et al. (2010), from which four factors were extracted with Factor Analysis, containing Fluency (eigenvalue $=2.554, \alpha=0.82$ ), Flexibility (eigenvalue $=1.847, \alpha=0.87$ ), Originality (eigenvalue $=1.521, \alpha=$ 0.83 ), and Elaboration (eigenvalue $=1.229, \alpha=0.88$ ). The covariance explained reached $76.158 \%$.

\subsection{Analysis of the effects of Curriculum Design on Creative Potential Developing}

(1) Analysis of the effects of Curriculum Design on Fluency in Creative Potential Developing

With Regression Analysis to test H1, see Table 1, Deliberation Process $(\beta=1.628, p<0.05)$ and Design Development $(\beta=1.922, p<0.05)$ had remarkable effects on Fluency in Creative Potential Developing that H1 was partially supported.

(2) Analysis of the effects of Curriculum Design on Flexibility in Creative Potential Developing

With Regression Analysis to test $\mathrm{H} 2$, see Table 1, Curriculum Platform $(\beta=1.733, \mathrm{p}<0.05)$ and Design Development $(\beta=1.874, \mathrm{p}<0.05)$ presented significant effects on Flexibility in Creative Potential Developing that H2 was partially supported.

(3) Analysis of the effects of Curriculum Design on Originality in Creative Potential Developing

With Regression Analysis to test H3, see Table 1, Curriculum Platform $(\beta=2.131, \mathrm{p}<0.01)$ and Design Development $(\beta=2.277, \mathrm{p}<0.01)$ showed notable effects on Originality in Creative Potential Developing that H3 was partially supported.

(4) Analysis of the effects of Curriculum Design on Elaboration in Creative Potential Developing

With Regression Analysis to test H4, see Table 1, Deliberation Process $(\beta=1.917, \mathrm{p}<0.05)$ and Design Development $(\beta=2.081, \mathrm{p}<0.01)$ revealed remarkable effects on Elaboration in Creative Potential Developing that $\mathrm{H} 4$ was partially supported. 
Table 1. Regression analysis of Curriculum Design and Creative Potential Developing

\begin{tabular}{|c|c|c|c|c|c|c|c|c|}
\hline $\begin{array}{l}\text { Dependent } \\
\text { variable } \rightarrow\end{array}$ & \multicolumn{8}{|c|}{ Creative Potential Developing } \\
\hline $\begin{array}{l}\text { Independent } \\
\text { variable } \downarrow\end{array}$ & \multicolumn{2}{|c|}{ Fluency } & \multicolumn{2}{|c|}{ Flexibility } & \multicolumn{2}{|c|}{ Originality } & \multicolumn{2}{|c|}{ Elaboration } \\
\hline Curriculum Design & $\beta$ & $\rho$ & $\beta$ & $\rho$ & $\beta$ & $\rho$ & $\beta$ & $\rho$ \\
\hline $\begin{array}{l}\text { Curriculum } \\
\text { Platform } \\
\end{array}$ & 1.136 & 0.217 & $1.733^{*}$ & 0.024 & $2.131^{*}$ & 0.000 & 0.834 & 0.627 \\
\hline $\begin{array}{l}\text { Deliberation } \\
\text { Process }\end{array}$ & $1.628^{*}$ & 0.031 & 1.044 & 0.338 & 1.233 & 0.197 & $1.917^{*}$ & 0.015 \\
\hline \begin{tabular}{|l|} 
Design \\
Development
\end{tabular} & $1.922 *$ & 0.013 & $1.874 *$ & 0.018 & $2.277 * *$ & 0.000 & $2.081 * *$ & 0.002 \\
\hline $\mathrm{F}$ & \multicolumn{2}{|c|}{11.853} & \multicolumn{2}{|c|}{17.652} & \multicolumn{2}{|c|}{23.347} & \multicolumn{2}{|c|}{31.368} \\
\hline Significance & \multicolumn{2}{|c|}{$0.000 * * *$} & \multicolumn{2}{|c|}{$0.000 * * *$} & \multicolumn{2}{|c|}{$0.000 * * *$} & \multicolumn{2}{|c|}{$0.000 * * *$} \\
\hline $\mathrm{R} 2$ & \multicolumn{2}{|c|}{0.242} & \multicolumn{2}{|c|}{0.275} & \multicolumn{2}{|c|}{0.317} & \multicolumn{2}{|c|}{0.351} \\
\hline Adjusted R2 & \multicolumn{2}{|c|}{0.022} & \multicolumn{2}{|c|}{0.027} & \multicolumn{2}{|c|}{0.036} & \multicolumn{2}{|c|}{0.42} \\
\hline
\end{tabular}

Note: $*$ stands for $\mathrm{p}<0.05, * *$ for $\mathrm{p}<0.01, * * *$ for $\mathrm{p}<0.001$

Data source: self-organized in this study

\subsection{Moderating effects of background variables}

(1) Moderating effects of Gender on the correlations between Curriculum Design and Creative Potential Developing

The empirical results with Analysis of Variance, see Table 2, presented the significant effects of Gender on the correlations between Deliberation Process $(\mathrm{P}<0.05)$, Design Development $(\mathrm{P}<0.05)$ and Fluency; between Deliberation Process $(\mathrm{P}<0.05)$, Design Development $(\mathrm{P}<0.05)$ and Flexibility; between Curriculum Platform $(\mathrm{P}<0.05)$, Deliberation Process $(\mathrm{P}<0.01)$ and Originality; and between Deliberation Process $(\mathrm{P}<0.01)$, Design Development $(\mathrm{P}<0.05)$ and Elaboration. H5 therefore was partially supported.

(2) Moderating effects of Family Condition on the correlations between Curriculum Design and Creative Potential Developing

The empirical results with Analysis of Variance, see Table 2, showed the remarkable effects of Family Condition on the correlations between Deliberation Process $(\mathrm{P}<0.05)$ and Fluency; between Curriculum Platform $(\mathrm{P}<0.01)$ and Flexibility; and between Curriculum Platform $(\mathrm{P}<0.05)$ and Originality. H6 therefore was partially supported.

(3) Moderating effects of School Year on the correlations between Curriculum Design and Creative Potential Developing

The empirical results with Analysis of Variance, see Table 2, revealed the notable effects of School Year on the correlations between Curriculum Platform 
Table 2. Effects of background variables on the correlations between Curriculum Design and Creative Potential Developing

\begin{tabular}{|l|l|c|c|c|c|}
\hline $\begin{array}{l}\text { Background vari- } \\
\text { ables }\end{array}$ & Curriculum Design & Fluency & Flexibility & Originality & Elaboration \\
\hline \multirow{4}{*}{ Gender } & Curriculum Platform & 0.133 & 0.088 & 0.011 & 0.423 \\
\cline { 2 - 6 } & Deliberation Process & 0.042 & 0.027 & 0.009 & 0.000 \\
\cline { 2 - 6 } & Design Development & 0.035 & 0.014 & 0.233 & 0.039 \\
\hline \multirow{4}{*}{ Family Condition } & Curriculum Platform & 0.162 & 0.007 & 0.045 & 0.055 \\
\cline { 2 - 6 } & Deliberation Process & 0.021 & 0.533 & 0.684 & 0.176 \\
\cline { 2 - 6 } & Design Development & 0.384 & 0.824 & 0.095 & 0.144 \\
\hline \multirow{3}{*}{ School Year } & Curriculum Platform & 0.047 & 0.002 & 0.000 & 0.033 \\
\cline { 2 - 6 } & Deliberation Process & 0.083 & 0.077 & 0.715 & 0.716 \\
\cline { 2 - 6 } & Design Development & 0.012 & 0.039 & 0.017 & 0.334 \\
\hline
\end{tabular}

Data source: Self-organized in this study

$(\mathrm{P}<0.05)$, Design Development $(\mathrm{P}<0.05)$ and Fluency; between Curriculum Platform ( $\mathrm{P}<0.01)$, Design Development $(\mathrm{P}<0.05)$ and Flexibility; between Curriculum Platform $(\mathrm{P}<0.01)$, Design Development $(\mathrm{P}<0.05)$ and Originality; and between Curriculum Platform $(\mathrm{P}<0.05)$ and Elaboration. $\mathrm{H} 7$ therefore was partially supported.

\section{CONCLUSION}

From Table 2, the better Curriculum Design could better enhance the creative potential. Apparently, Creative Potential Developing could be cultivated through various teaching activities. In this case, Curriculum Design should allow teachers introducing knowledge and materials with lively and vivid approaches and students being glad to learn. Furthermore, the introduction of invention, patent, and creation could motivate students to create and invent. The practice of originality skills could have students be familiar with applying various skills to creation and invention. Several types of Curriculum Design could assist students in the collaborative instruction of originality thinking and problem-solving in Creative Potential Developing. It is therefore expected to assist students in learning and developing with the assistance of teachers and peers so that the students' zone of proximal development could be maximized. Besides, the students are encouraged to explore natural affairs, led to discover the defects, imperfection, or specialty, and observe the reaction to revise the learning attitudes so as to enhance the students' Creative Potential Developing. 


\section{SUGGESTION}

According to the above analyses, the following suggestions are proposed in this study.

1. Lead the students to the effective interaction with the environment

Curriculum developers should present consistent belief and purpose on curriculum meaning and educational perspective. When Curriculum Platform is based on Deliberation Process, the teaching and learning approaches and contents should be definitely indicated so that the teachers could flexibly apply the materials, lead the students actively and effectively interacting with the environment and exploring any possible affairs to induce innovation; with inductive thinking to establish and verify hypotheses, the common attributes and the principles of such affairs could be found out; timely providing some creative skills for the students could have the students find out the acting point. In this case, originality will be ubiquitous and the world will be beautiful because of constant creation.

2. Decorate conceptual conflict situations or proceed the teaching strategies of concept changing

Curriculum Design focuses on the curriculum design and development in classrooms that teachers could decorate the conceptual conflict situations or precede the teaching strategy of concept changing, aiming at the students' misconceptions when designing teaching activities. Meanwhile, aiming at students' misconceptions to ask questions in class, the students are induced the creative thinking by being encouraged to speak out. Moreover, peer discussions and cooperative learning model could be applied to clarifying the misconceptions.

3. Design and develop students' habits to pursue the perfection

Students, as the main role, are responsible for interpreting the experiences and actively constructing the meaning. As a result, students can be asked for discussions or debate on controversial problems, when the teacher plays the role of a neutral host. The students can freely express the opinions so that the classroom becomes a forum. Discussions and exploration, rather than inculcating the teaching materials, can be utilized for leading the students accustomed to deliberate thinking, precise analyses, and pursuing perfect. 


\section{REFERENCES}

Amabile, T. (1983). The Social Psychology of Creativity. New York: Springer-Verlag.

Ausubel, D.P. et al. (1978). Educational Psychology: A Cognitive View, 2nd ed. New York: Holt, Rinehart and Winston

Banks, J. A. (1996). Multicultural Education, Transformative Knowledge and Action: Historical and Contemporary Perspectives. New York: Teachers College Press.

Biagetti, M. and Scicchitano, S. (2013). The determinants of lifelong learning incidence across European countries (evidence from EU-SILC dataset). Acta Oeconomica, 63(1), 77-97.

Davis, G.A. (1986). Creativity is Forever. Iowa: Kendall /Hunt Publishing Company.

Davis, G.A. (1997). Handbook of Gifted Education. Allyn \& Bacon.

Elliott, J. (1991). Action Research for Educational Change. Philadelphia: Open University.

Feldhusen, J.F. and Treffinger, D.J. (1980). Creative Thinking and Problem Solving in Gifted Education. Texas: Kendall/Hunt Publishing Company.

Guilford, J.P. (1956). The structure of intellect. Psychological Bulletin, 52.

Guilford, J.P. (1968). Intelligence, Creativity and their Educational Implications. San Diego: Robert R. Knapp.

György, L. (2014). Main challenges of Hungarian public education with special focus on inequality: An international comparison. Acta Oeconomica, 64(1), 1-26.

Harris, V. (2008). Applying research in creativity and skill acquisition in a Community-based creative writing program: Implications for teachers and learners, Teaching Artist Journal. 6(3), 209-219.

Hocevar, D. (1981). Measurement of creativity review and critique. Journal of Personality Assessment, 45(5), 450-464.

Johnson, B. (1993). Teacher-As-Researcher. ERIC Digest.

Kincheloe, J.L. (1993). Teachers as researchers: Qualitative inquiry as a path to empowerment. Basingstoke: Falmer.

Lin, P.Y., Hsieh, C.L., Chang, C.L. and Hung, C.H. (2014). Exploring the athlete's sports learning effect based on leader-member exchange theory - college class $A$ team of Taiwan as example. Acta Oeconomica, 64(Supplement 2), 127-149.

Lytton, H. (1972). Creativity and Education. New York: Schocken Books Inc.

Morrison, A. and Johnston, B. (2006). Personal creativity for entrepreneurship: teaching and learning strategies. Active Learning in Higher Education, 4, 415.

Noffke, S.E. (1997). Professional, personal, and political dimension of action Research. Review of Research in Education, 22, 305-342.

Parnes, S.J. (1967). Creative Behavior Guidebook. New York: University State of New York College.

Stringer, E.T. (1996). Action Research: A Handbook for Practitioners. Thousand Oaks, CA: Sage.

Sternberg, R.J. and Lubart, T.I. (1995). Investing in creativity. American Psychologist, 51(7), $677-$ 688.

Sternberg, R.J. and Lubart, T.I. (1999). The concept of creativity: Prospects and paradigms, Handbook of Creativity. New York: Cambridge University Press.

Tsai, Q. (2008). Constructivism oriented curriculum design. Curriculum and Instruction Quarterly, 1(3), 15-30.

Walker, D.F. (1990). Fundamentals of Curriculum. New York: Harcourt Brace Jovanovich.

Wright, C. and Fesler, L.L. (1990). Nurturing creative potentials: model early childhood program. In C.W. Taylor (ed.), Expanding Awareness of Creative Potentials Worldwide. Salt Lake, Ut.: Braib Talent-powers.

Wu, C., Chen, J. and Lin, W, (2010), About creativity scale. Chung Shan Management Review, $3(2), 68-82$. 